\title{
Quality of Life and Gait in Elderly Group
}

\author{
Carlos Kazuo Taguchi ${ }^{1}$ Jacqueline Pitanga Teixeira ${ }^{2}$ Lucas Vieira Alves ${ }^{2}$ Priscila Feliciano Oliveira ${ }^{2}$ \\ Oscar Felipe Falcão Raposo ${ }^{2}$
}

${ }^{1}$ Audiology Department, Universidade Federal de Sergipe, São Cristovão, Sergipe, Brazil

2 Statistics Department, Universidade Federal de Sergipe, São Cristovão, Sergipe, Brazil

\author{
Address for correspondence Carlos Kazuo Taguchi, PhD, Audiologia, \\ Universidade Federal de Sergipe, Av. Mal Rondon s/n Rosa Elze, São \\ Cristóvão, Sergipe 49700000, Brazil \\ (e-mail: carlostaguchi@hotmail.com).
}

Int Arch Otorhinolaryngol 2016;20:235-240.

\begin{abstract}
Introduction The process of aging could lead to seniors being more prone to falls, which affects their quality of life.

Objective The objective of this study is to investigate the relationship between quality of life and gait in the elderly.

Methods We used World Health Organization Quality of Life-Brief (WHOQOL-Brief) Brazilian version and the Dynamic Gait Index to assess fifty-six volunteers from the northeast of Brazil. Ages ranged from 60 to 85 years.

Results The Dynamic Gait Index, which indicates the probability of falls, resulted in $36.3 \%$ of the sample presenting abnormal results. There was correlation between domain 2 (psychological) and domain 4 (environment) with domain 1(Physical) and domain 3 (Social); a negative correlation between age and Domain 2; correlation between Question 1 (How would you rate your quality of life?) and domains 1, 2, and 4 and no correlation between questions 1 and 2 (How satisfied are you with your health?). Question 2 was correlated with all of the domains. There was negative association

Keywords

- aged

- gait

- postural balance

- accidental falls between question 1 and falls, and a slight correlation between the Dynamic Gait Index scores and Question 1.

Conclusion The self-perception of the study group about their quality of life was either good or very good, even though a considerable percentage of individuals had suffered falls or reported gait disturbances.
\end{abstract}

\section{Introduction}

Senescence, a natural, current and irreversible fact, is accompanied by the decline of many systems and functions that compromise human balance, which includes the vestibular system. Vestibular disorders are frequent in the elderly people and causes dizziness and body imbalance, symptoms that may impair daily activities. There is a positive correlation between balance and functional ability in elderly patients with peripheral vestibular disorders. The better the balance performance, the better the functional capacity. Conversely, an inferior functional capacity increases the risk of falls in subjects. Aging brings several changes in body systems, resulting in a higher frequency of falls and, therefore, a potentially negative impact on quality of life. ${ }^{1}$

There is a correlation between risk of falls and age. The annual incidence of falls in people over 65 is $25 \%$ and $50 \%$ in those over 80 years old. Studies show that $30 \%$ of people over 65 years of age fall at least once a year and that falls are responsible for $70 \%$ of accidental deaths in people older than 75 years. $^{2}$

Falls commonly correlate with dizziness and may result in serious consequences and harm for elderly quality of life, increasing dependency. The functional limitations imposed by the symptom causes physical and psychological injuries and inability to perform daily and work activities. ${ }^{3}$ received

June 18, 2015

accepted

September 28, 2015

published online

December 15, 2015
DOI http://dx.doi.org/

10.1055/s-0035-1570313. ISSN $1809-9777$.
Copyright $\odot 2016$ by Thieme Publicações License terms

Ltda, Rio de Janeiro, Brazil 
It is important for elderly people to be able to perform their daily activities, maintain functions, and retain their independence and autonomy. The association between falls and quality of life pointed to factors such as wellness, self-esteem, functionality, culture, ethics, religion, home environment, and health as key in determining quality of life. ${ }^{4}$

Studies have shown that the elderly paradigm has been modified and that several factors contribute to healthy aging, including physical and mental health, family support, clinical monitoring, social integration, and financial and daily independence. ${ }^{5}$ Falls may result in instability, postural imbalance, fear of falling, depression, isolation, and negative self-perception with respect to their independence. ${ }^{4}$

The risk of falling may induce fear of falls. Many older adults experience fear of falling, which may reduce their participation in routine activities. ${ }^{6}$ Such features should include intervention of all health professionals, considering that falls could be associated with several causes and implies a considerable amount of health care costs. These intervention programs are effective in reducing fear of falling among older adults. ${ }^{7}$

Our research could not verify the correlation between the World Health Organization Quality of Life (WHOQOL) and the Dynamic Gait Index (DGI).

\section{Objective}

The objective of this study was to evaluate the quality of life and gait in a healthy elderly group, as well as to assess quality of life and balance with respect to gender, age, and frequency of falls.

\section{Methods}

This is a clinical, exploratory, descriptive, and qualitative study using the World Health Organization Quality of LifeBrief (WHOQOL-Brief) and the Dynamic Gait Index (DGI) to study an elderly group from the northeast of Brazil. This study was submitted to the Ethics and Research Center of Medicine of the Institution, which approved and registered the projects with the following numbers: 0198.0.107.000-09 and 6232.0.000.107-10.

Data collection and evaluations were performed in a private office in the city of Aracaju and at a Family Health Public Center in Itabaiana city. We started with a brief interview to collect preliminary data from the volunteers, listing inclusion and exclusion criteria, complaints of dizziness, and reported falling events. The final sample comprised 47 females and 9 males, retired, not institutionalized, and without regular practice of physical activities.

Volunteers were selected if they met the following two inclusion criteria: 1) they were over 60 years old; 2) they presented no cutoff score less than 19 points on the MiniMental State Examination. ${ }^{8}$ For data analysis, we used the proposition derived from the study of Herrera Jr., Caramelli, Nitrini, ${ }^{9}$ as shown in - Tables $\mathbf{1}$ and $\mathbf{3}$. They demonstrated good comprehension of the test questions.
Volunteers were excluded from the study if they were using medical drugs that could influence their level of awareness; if they presented signs of dementia; if they demonstrated hearing loss without a hearing aid; if they had comprehension difficulties; or if they had a limited or abnormal gait.

To evaluate the quality of life, we used the Brazilian version of the WHOQOL, validated by Fleck et $\mathrm{al}^{10}$, which is a selfassessment and self-explanatory inventory. There are 26 questions in the WHOQOL-brief: two address life quality issues and the other 24 represent the original instrument facets. It is important to observe that this inventory has no cutoff point because it considered a self-related perception, mainly in two questions: "How would you rated your quality of life?" and "How satisfied are you with your health?".

The WHOQOL-brief is divided in four domains: physical (domain 1), psychological (domain 2), social (domain 3), and environment (domain 4).

Physical domains include: daily activities; dependence on medicinal substances and medical aids; energy and fatigue; mobility pain and discomfort; sleep and rest; work capacity.

The psychological domain refers to: bodily image and appearance; negative feelings; positive feelings; self-esteem spirituality / religion / personal beliefs; thinking, learning, memory and concentration.

Social relationships include: personal relationships; social support; sexual activity. The environment domain refers to: financial resources; freedom, physical safety and security. Health and social care include: accessibility and quality; home environment; opportunities for acquiring new information and skills; participation in and opportunities for recreation / leisure activities; physical environment (pollution / noise / traffic / climate); transport.

To evaluate the gait, we used the DGI developed by Shummway-Cook et $\mathrm{al}^{11}$, adapted to the Brazilian language by Castro et al. ${ }^{12}$ In the DGI, there are eight tasks that evaluate and characterize balance during gait in different functional contexts. According to the standard reported by Castro et al ${ }^{12}$, the score $\leq 19$ points indicates a gait disturbance and predicts falling risks.

For statistical purposes, we used the summarized results (mean, median, standard deviation, confidence interval above and below 95\%, absolute and relative frequency), and the Alpha $(\alpha)$ Cronbach test, Chi-square (X2), Pearson's test, and Spearman's test. We considered results lower than $0.05 \%$ $(p<0.05)$ and lower than $0.01 \%(p<0.01)$ significant, which are indicated with one or two asterisks, respectively.

\section{Results}

There were a total of 56 volunteers: $83.9 \%$ women and $16.1 \%$ men. Their age ranged from 60 to 83 years and average age was 69.9 years. From the general sample, Cronbach́s test revealed an $\alpha$ of 0.76 , being 0.75 for female and 0.83 for male. The $\alpha$ value ranged from $98.2 \%$ to $100 \%$ for the correlations between the domains, DGI, and gender. This score indicated the high reliability of our results. 
Table 1 Distribution according the level of education on the Mini-Mental State Examination

\begin{tabular}{|l|l|l|l|l|}
\hline Schooling & No schooling & $\geq \mathbf{1}$ and $\leq \mathbf{8}$ years & $\geq \mathbf{9}$ and $\leq \mathbf{1 1}$ years & $\geq \mathbf{1 2}$ years \\
\hline Score & 19 & 24 & 24 & 28 \\
\hline
\end{tabular}

Table 2 Statistical Distribution of the Dynamic Gait Index scores by Domain 1 (physical), 2 (psychological), 3 (social) and 4 (environment)

\begin{tabular}{|l|l|l|l|l|l|}
\hline & Dynamic Gait Index & Physical & Psychological & Social & Environment \\
\hline Dynamic Gait Index & 1 & -0.136 & -0.167 & 0.124 & -0.003 \\
\hline Physical & -0.136 & 1 & $0.413^{* *}$ & 0.140 & $0.547^{* *}$ \\
\hline Psychological & -0.167 & $0.413^{* *}$ & 1 & $0.474^{* *}$ & $0.624^{* *}$ \\
\hline Social & 0.124 & 0.140 & $0.474^{* *}$ & 1 & $0.383^{* *}$ \\
\hline Environment & $-0.003^{*}$ & $0.547^{* *}$ & $0.624^{* *}$ & $0.383^{* *}$ & 1 \\
\hline
\end{tabular}

Pearson correlation test.

Table 3 Correlation between age and Domains 1 (physical), 2 (psychological), 3 (social) and 4 (environment) of the sample

\begin{tabular}{|l|l|l|l|l|l|}
\hline & Age & Physical & Psychological & Social & Environment \\
\hline Age & 1 & 0.111 & $-0.004^{* *}$ & 0.075 & 0.164 \\
\hline Physical & 0.111 & 1 & $0.413^{* *}$ & 0.140 & $0.547^{* *}$ \\
\hline Psychological & $-0.004^{* *}$ & $0.413^{* *}$ & 1 & $0.474^{* *}$ & $0.624^{* *}$ \\
\hline Social & 0.075 & 0.140 & $0.474^{* *}$ & 1 & $0.383^{* *}$ \\
\hline Environment & 0.164 & $0.547^{* *}$ & $0.624^{* *}$ & $0.383^{* *}$ & 1 \\
\hline
\end{tabular}

Pearson correlation test.

* P lower than $0.05 \%(p<0.05)$, significant.

** $P$ lower than $0.01 \%(p<0.01)$, significant.

- Table 2 shows the statistical results of the Pearson correlation which analyzes the scores of DGI, Domain 1 (physical), Domain 2 (psychological), Domain 3(social relationships), and Domain 4 (environment). The Pearson correlation test detailed in - Table 2 reveals a positive correlation between Domains 2 and 4 and the other domains.

We used the Pearson correlation to analyze the age and Domain 1, 2, 3, and 4 variables. The results, shown in -Table 3, indicate a significant negative correlation between age and Domain 2.
We used Spearman's test to analyze the responses to Question 1 (How would you rate your quality of life?), Question 2 (How satisfied are you with your health?), Domain 1, Domain 2, Domain 3, Domain 4. The results are shown in -Table 4. Spearman's test revealed a significant correlation between Question 1 and Domains 1, 2, and 4 and no correlation between Questions 1 and 2. Question 2 was correlated with all of the domains.

We used Spearman's test to analyze the responses to Questions 1 and 2, DGI scores, and falls, as shown

Table 4 Correlation between the responses to Questions 1 (How would you rate your quality of life?) and 2 (How satisfied are you with your health?) and Domains 1 (physical), 2 (psychological), 3 (social) and 4 (environment) using Spearman's test of the sample

\begin{tabular}{|l|l|l|l|l|l|l|}
\hline Spearman Correlation & Question 1 & Question 2 & Physical & Psychological & Social & Environment \\
\hline Question 1 & 1.000 & 0.222 & $0.493^{* *}$ & $0.516^{* *}$ & 0.234 & $0.527^{* *}$ \\
\hline Question 2 & 0.222 & 1.000 & $0.467^{* *}$ & $0.429^{* *}$ & $0.355^{* *}$ & $0.442^{* *}$ \\
\hline Physical & $0.493^{* *}$ & $0.467^{* *}$ & $0.571^{* *}$ & $0.392^{* *}$ & 0.156 & $0.571^{* *}$ \\
\hline Psychological & $0.516^{* *}$ & $0.429^{* *}$ & $0.648^{* *}$ & 1.000 & $0.533^{* *}$ & $0.648^{* *}$ \\
\hline Social & 0.234 & $0.355^{* *}$ & $0.346^{* *}$ & $0.533^{* *}$ & 1.000 & $0.346^{* *}$ \\
\hline Environment & $0.527^{* *}$ & $0.442^{* *}$ & 1.000 & $0.648^{* *}$ & $0.346^{* *}$ & 1.000 \\
\hline
\end{tabular}

Spearman's test.

Abbreviation: Q, question. 
Table 5 Correlation between Questions 1 (How would you rate your quality of life?) and 2 (How satisfied are you with your health?), related falls and DGI of the sample

\begin{tabular}{|l|l|l|l|l|}
\hline & Question1 & Question 2 & Dinamic Gait Index & Falls \\
\hline Question 1 & 1 & 0.222 & $-0.066^{*}$ & $-.038^{*}$ \\
\hline Question 2 & 0.222 & 1 & -0.254 & -0.138 \\
\hline Dynamic Gait Index & $-0.066^{*}$ & -0.254 & 1 & -0.151 \\
\hline Falls & $-0.038^{*}$ & -0.138 & -0.151 & 1 \\
\hline
\end{tabular}

Spearman's test.

in -Table 5. The results revealed a negative association between Question 1 and falls, as well as a slight correlation between the DGI scores and Question 1.

Of the volunteers who reported falls, $72.7 \%$ reported having a good quality of life and $54.5 \%$ said that they were neither satisfied nor dissatisfied with their health. Even though the Pearson correlation test revealed no significant correlations between Question 1 and 2 and gait complaints, a considerable portion (68.6\%) of the volunteers reported a good quality of life, regardless of imbalance. In addition, 40.0\% of them reported being satisfied with their health.

\section{Discussion}

In contrast to some studies, our statistical analysis indicates that gender does not affect the WHOQOL-Brief results. ${ }^{13,14}$ These studies have reported that the quality of life in elderly females is lower with respect to physical health, functional capacity and social and cognitive activities, in comparison to males of the same age who had a better perception of their quality of life. However, another study, which indicated that the presence or absence of satisfaction with quality of life was not associated with gender, concurs with our results. ${ }^{15}$

We showed that gender does not interfere with DGI tasks, as reported by a previous study. ${ }^{16}$ However, some studies have reported that female volunteers obtain better results than male volunteers, a conclusion that is not in accordance with our results. ${ }^{17}$

In our study, age did not correlate with the WHOQOL-Brief. Other research revealed similar results, ${ }^{18}$ although these are in contrast to other studies which have reported that senescence induces health problems, financial weakness, depression, social and emotional isolation, and reduced autonomy and productivity. Together, these factors contribute to a reduction in the quality of life. ${ }^{19}$

We found that age did not affect the DGI score, which concurs with a study by Whitney. ${ }^{16}$ This is, however, in contrast to the results reported by another study that found that age influences both gait and balance in elderly people. ${ }^{20}$

Out of the volunteers who reported falls, 36.3\% had low DGI scores, indicating that this is a useful measure for evaluating gait and predicting the risk of falling. Other studies have also indicated that DGI is a good way to assess the ability to adapt to changes in gait during some tasks. ${ }^{17,20}$

We did not find any correlation between fall frequency and age, though this relationship has been reported by other authors. $^{21}$ Previous studies have reported that females are prone to accidental falls at a younger age than males because women reach their peak muscular performance earlier in life. Therefore, body functions, balance, and gait may decline earlier in women. We did not find any evidence to support this theory in our study. ${ }^{13}$

As shown by - Table 1, we found that domains 2 (psychological) and 4 (environment) were correlated with all domains, indicating that satisfaction with environment is associated with good mental health. Financial proceeds decline is related to decrease in age, whereas satisfaction correlates with an individual's personal life and stress status, estimated using in domains 2 and 4. Inappropriate environment organization binds elderly autonomy and independence. This causes a decrease in functional capacity and self-esteem, in addition to falls and fear of falling, resulting in social isolation and depression. ${ }^{22,23}$

Our study shows that psychological and environment domains are strongly connected, which concurs with previous research. ${ }^{24}$ In addition, the environment domain is considered to be a strong influence on the overall quality of life.

We observed a negative correlation between age and Domain 2, in other words, the older the subject the lower their score in psychological domain. At present, there is no consensus regarding this relationship, as different studies have reported contrasting results. The presenting results are similar to that of other studies. ${ }^{25,26}$

We found a correlation between Question 2 (How satisfied are you with your health?) and all of the domains from the WHOQOL-Brief. This correlation has also been observed in other studies, which stated that general health includes physical, psychological, environmental, and social aspects, all of which are important for independence and autonomy in elderly groups. ${ }^{27}$

In elderly people, the physical, mental, and environmental aspects which determine a good quality of life were shown by the correlation between Question 1 (How would you rate your quality of life?) and domains 1 (physical), 2 (psychological), and 4 (environment). This correlation has also been reported by other studies. ${ }^{25,28}$

As well presented, the question 1 and 2 are correlated subjects, but not similar. We did not expect our sample to show close answers. Our hypothesis is that this event could be explained by the link between quality of life and health, which often appear synonymous because these questions are 
assessed almost simultaneously. Other studies have suggested this as well. ${ }^{29}$ Such studies indicate that quality of life is connected to the individual's perception of their health status and to general aspects of their life. Our statistical analysis showed that volunteers perceived good health and quality of life to be similar.

We found a negative association between Question 1 and fall frequency. The volunteers who reported a good quality of life experienced fewer falls, a result which concurs with other studies. ${ }^{30,31}$ We believe that fall frequency is an important factor to consider when assessing dependency and quality of life.

For Question 1, 72.7\% of volunteers who had reported a fall also reported good quality of life. There was a misperception of the volunteers about their welfare, since that which related to falls did not affect their judgment of their quality of life. Previous research showed that falls affect quality of life of those prone to falls. ${ }^{17}$ The same pattern was observed for the second question (54.5\%), indicating that social, environmental, and psychological aspects may have influenced the perception of the subjects. We observed that high scores in other questions affected the importance of fall events, especially when they were sporadic.

A considerable percentage of our sample reported good quality of life and satisfaction with their health, in addition to balance complaints. This led us to believe that positive responses did not follow the same pattern as other studies, some of which showing that complaints and gait disorders directly affect quality of life and health. ${ }^{32}$

The quality of life is determined by an individual's selfperception, therefore, it is subjective. Various factors are considered including lifestyle, expectations, motivations, and psychological state. ${ }^{2,5}$ This subjectivity and range of factors allow for mixed results, for example, two subjects with the same disease which respond differently to questions regarding their quality of life and health. Therefore, we believe that dizzinesś complaints do not influence an individual's self-perception of their quality of life and health.

\section{Conclusion}

In this study, we found that the quality of life and health of elderly people was adequate in the presence of complaints and gait disorders, which was unexpected. According to the WHOQOL-Brief, the quality of life of the subjects was either good or very good, even when a considerable percentage reported falls and gait disturbances. Gender and age did not affect quality of life assessment or DGI, neither were these factors associated with falls.

\section{References}

1 Sousa RF, Gazzola JM, Ganança MM, Paulino CA. Correlação entre equilíbrio corporal e capacidade funcional de idosos com disfunções vestibulares crônicas. Braz J Otorhinolaryngol 2011;77(6): 10.1590/S1808-86942011000600017
2 Hanmer J. Increasing number of unintentional falls indicates urgent need for fall prevention programs. J Am Geriatr Soc 2010;58(3):603-604

3 Ganança MM. Vestibular disorders in the elderly. Braz J Otorhinolaryngol 2015;81(1):4-5

4 Chang NT, Chi LY, Yang NP, Chou P. The impact of falls and fear of falling on health-related quality of life in Taiwanese elderly. J Community Health Nurs 2010;27(2):84-95

5 Horton K, Dickinson A. The role of culture and diversity in the prevention of falls among older Chinese people. Can J Aging 2011; 30(1):57-66

6 Batra A, Melchior M, Seff L, Frederick N, Palmer RC. Evaluation of a community-based falls prevention program in South Florida, 2008-2009. Prev Chronic Dis 2012;9:E13 10.5888/pcd9.110057

7 Hartholt KA, van Beeck EF, Polinder S, et al. Societal consequences of falls in the older population: injuries, healthcare costs, and longterm reduced quality of life. J Trauma 2011;71(3):748-753

8 Almeida OP. [Mini mental state examination and the diagnosis of dementia in Brazil]. Arq Neuropsiquiatr 1998;56(3B):605-612

9 Herrera Junior And Caramelli P. R. Nitrini Epidemiological study of dementia in the city of Catanduva - State of São Paulo - Brazil. J Psiq Clin 1998;25:70-73

10 Fleck MP, Louzada S, Xavier M, et al. Aplicação da versão em português do instrumento abreviado de avaliação da qualidade de vida "WHOQOL-bref". Rev Saude Publica 2000;34(2):178-183

11 Shumway-cook A, Woolacott MH. Control of posture and balance. In: Shumway-Cook A, Woolacott MH. Motor Control Theory and Practical Applications. Maryland: Williams \& Wilkins; 1995:120

12 Castro SMD, Perracini MR, Gananca FF. Versão Brasileira do Dynamic Gait Index. Braz J Otorhinolaringol 2006;72(6):817-825

13 Dawalibi NW, Monteiro RM, Goulart RC, Witter C, Ameida M, Buriti LC. Índice de desenvolvimento humano e qualidade de vida de idosos frequentadores de universidades abertas para a terceira idade. Psicol Soc 2014;26(2):496-505

14 Almeida Moreira P, Roriz AKC, Mello AL, Ramos LB. Quality of Life of Institutionalized Elderly in Brazil. Soc Indic Res 2015;xx:1-11 10.1007/s1125015-0888-7

15 Vitorino LM, Paskulin LG, Vianna LAC. Quality of life among older adults resident in long-stay care facilities. . Rev Latino-Am Enfermagem 2012;20(6):1186-1195

16 Sasaki AC, Pinto EB, Mendel T, Sá KN, Oliveira-Filho J, D’Oliveira A Jr. Association between dual-task performance and balance during gait in community-dwelling elderly people after stroke. Healthy Aging Res 2015;4:29 10.12715/har

17 Baetens T, De Kegel A, Calders P, Vanderstraeten G, Cambier D. Prediction of falling among stroke patients in rehabilitation. J Rehabil Med 2011;43(10):876-883

18 Grzanka-Tykwińska A, Małgorzata C, Kornelia K. Evaluating the quality of life of elderly people who attend classes at the University of the Third Age. Med Biol Sci 2015;28(4):19-24

19 Ostrzyżek A. Ocena jakości życia osób w podeszłym wieku, rehabilitowanych w oddziale opieki długoterminowej. Probl Hig Epidemiol 2010;91:659-666

20 Alves LV, Gois IO, Taguchi CK, Oliveira IL, Sousa MGC. Evaluation the tendency to falls in elderly Sergipe. Rev CEFAC 2014;16(5): 1389-1396

21 Cho SI, An DH. Effects of a Fall Prevention Exercise Program on Muscle Strength and Balance of the Old-old Elderly. J Phys Ther Sci 2014;26(11):1771-1774

22 Close JC, Lord SR, Antonova EJ, et al. Older people presenting to the emergency department after a fall: a population with substantial recurrent healthcare use. Emerg Med J 2012;29(9):742-747

23 Prata HL, Junior EDDA, Louro JQ, De Lima PF, Santos JJN, Ferreira SM. Reports of falls extrinsic in elderly participants of a falls prevention project. J Research 2014;6(2):685-694

24 Park NS, Jang Y, Lee BS, Chiriboga DA. Relationship between perceived neighborhood environment and depressive symptoms 
in older Korean Americans: Do chronic disease and functional disability modify it? Asian Am J Psychol 2015;6(2):174-180

25 Ahmed A, Chaudhry AG, Afzal MI, Farooq H. Loneliness and diseases prevalence; a gerontological perspective of elder's disease status. Prof Med J 2015;22(3):343-348

26 Biolchi CS, Portella MR, Colussi EL. Vida e velhice aos 100 anos de idade: percepções na fala dos idosos. Estudos Interdisciplinares sobre o Envelhecimento. . Estud Interdiscipl Envelhec 2014;19(2): 583-598

27 Batistoni SST, Prestes SM, Cachioni M, et al. Categorização e Identificação Etária em uma Amostra de Idosos Brasileiros Residentes na Comunidade. Psicol Reflex Crit 2015;28(3):511-521

28 Dickens AP, Richards SH, Hawton A, et al. An evaluation of the effectiveness of a community mentoring service for socially isolated older people: a controlled trial. BMC Public Health 2011;11:218

29 Silva FCM, Silva HRO. Bem estar subjetivo, funcionalidade e apoio social em idosos da comunidade. Estud Interdiscipl Envelhec 2014;19(3):775-791

30 Karinkanta S, Piirtola M, Sievänen H, Uusi-Rasi K, Kannus P. Physical therapy approaches to reduce fall and fracture risk among older adults. Nat Rev Endocrinol 2010;6(7):396-407

31 Jahn K. [Gait disorders in the elderly: prospects for a symptomatic therapy]. Fortschr Neurol Psychiatr 2012;80(5):260-266

32 Lahmann C, Henningsen P, Brandt T, et al. Psychiatric comorbidity and psychosocial impairment among patients with vertigo and dizziness. J Neurol Neurosurg Psychiatry 2015;86(3): $302-308$ 